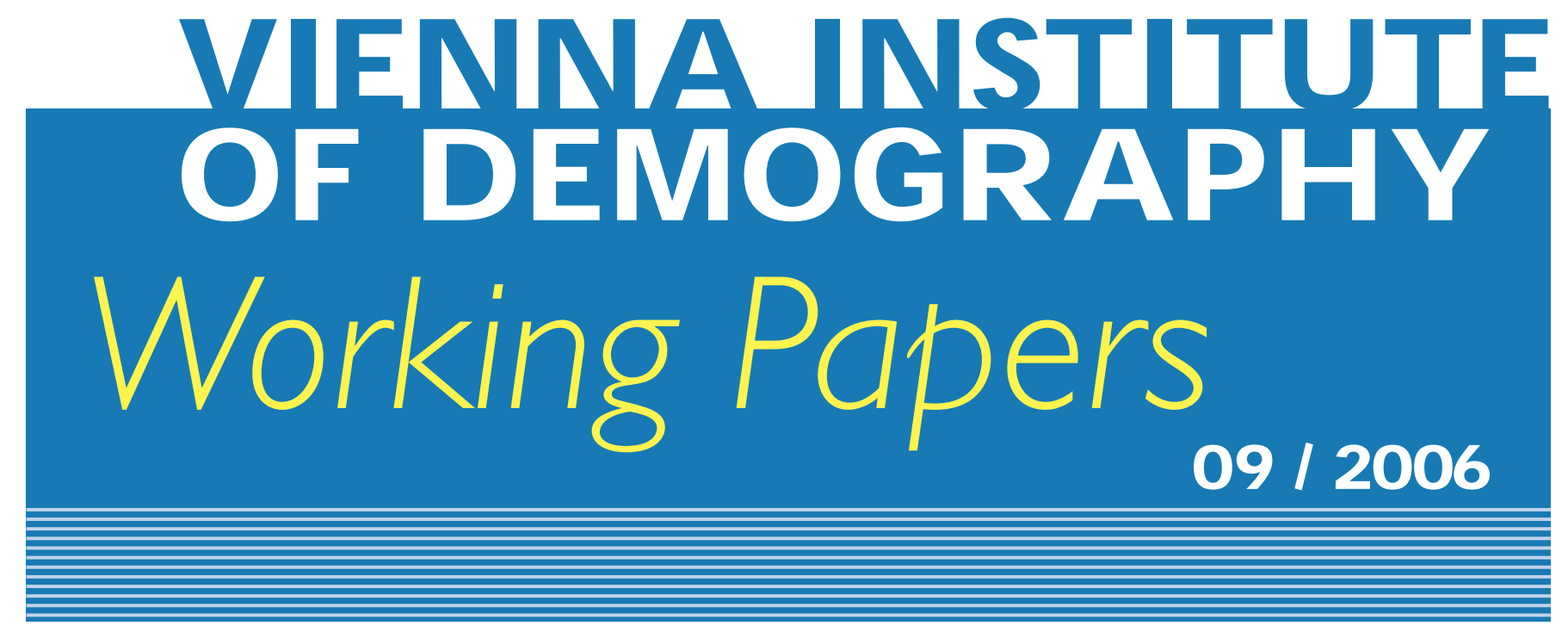

Alexia Prskawetz, Marija M amolo, and Henriette Engelhardt

\title{
Reconsidering the Relation between Fertility and Key Fertility-Related Demographic Behaviour across Space and Time
}

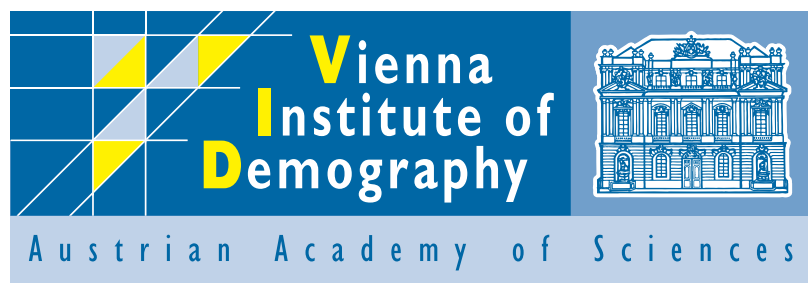

Vienna Institute of D emography Austrian A cademy of Sciences

Prinz Eugen-Straße 8-10 · A-1040 Vienna · A ustria

E-Mail: vid@ oeaw.ac.at

W ebsite: www.oeaw.ac.at/vid 


\begin{abstract}
Recent studies on fertility in Europe indicate the changing cross-country correlation between fertility and key fertility-related indicators. Fertility now tends to be lowest in countries that are traditional, catholic and family oriented, while fertility is highest in countries with high divorce rates, high rates of cohabitation and high levels of extra-marital fertility. In this paper we provide support to the argument that the change in the crosscountry correlation between fertility and fertility-related behaviour may indicate a change in social context of this fertility-related behaviour that has helped to uncover cross-country differences in social norms, culture and institutional settings. We apply pooled time series analysis and show that time and country heterogeneity in the effect of key-fertility related behaviour on fertility can explain the change in the cross-country correlation. Our results also indicate that further postponement of key-fertility related behaviour results into less pronounced declines in fertility.
\end{abstract}

\title{
Keywords
}

Cross-country correlation, low fertility, mean age at first birth, mean age at first marriage, total divorce rate, extra-marital birth, postponement of fertility, pooled time series analysis

\section{Authors}

Alexia Prskawetz is a Senior Scholar at the Vienna Institute of Demography of the Austrian Academy of Sciences, Vienna, Austria, and a Research Associate at the Institute for Social and Economic Research at University Essex, Colchester, U.K.

Email: alexia.fuernkranz-prskawetz@oeaw.ac.at

Marija Mamolo is a researcher at the Vienna Institute of Demography, Austrian Academy of Sciences. Email: marija.mamolo@oeaw.ac.at

Henriette Engelhardt is Professor of Demography at the University of Bamberg. Email: henriette.engelhardt-woelfler@sowi.uni-bamberg.de

\section{Acknowledgements}

We thank Sylvia Trnka for English editing of the paper. 


\title{
Reconsidering the Relation between Fertility and Key Fertility- Related Demographic Behaviour across Space and Time
}

\author{
Alexia Prskawetz, Marija Mamolo, Henriette Engelhardt
}

\section{Introduction}

Cross-country differentials in period fertility rates are commonly explained by cross-country differentials in socio-economic, demographic, cultural and institutional settings. Recent studies have indicated "... a reversal of many well-known relationships that have been used to explain cross-country differences in fertility patterns" (Billari and Kohler 2004, p. 161). Fertility now tends to be lowest in countries that are traditional, catholic and family oriented. On the opposite, fertility is highest in countries with high divorce rates, highest rates of cohabitation and the greatest level of extra-marital fertility (Monnier and de Guibert-Lantoine 1996). As Castles (2002, p. 22) argued, "In a world where socioeconomic and cultural patterns are usually slow to change, there has been a radical reversal in traditional factors that influence levels of fertility".

One of the most studied phenomena in this respect is the change in the cross-country correlation between the total fertility rate and female labour force participation which turned from a negative value before the 1980s to a positive value thereafter (cf. EspingAndersen 1999; Brewster and Rindfuss 2000; Ahn and Mira 2002; Pampel 2001; Rindfuss et al. 2003). Studies by Engelhardt et al. (2004) and Kögel (2004) have shown that neither the causality nor the time series association between total fertility and female labour force participation has changed over time. Theories that explain the change in the cross-country correlation have been advocated by Benjamin (2001), Pampel (2001), Ahn and Mira (2002), Castles (2002), Adsera (2004), Engelhardt and Prskawetz (2004) and de Laat and Sevilla-Sanz (2005).

As the study by Engelhardt and Prskawetz (2004) showed, trends in the labour market (male labour participation rate, male and female unemployment rate, gender wage gap) and demographic indicators (female first marriage rate, total divorce rate, mean age at first birth) are compatible with the overall drop in total fertility according to the theories of the New Home Economics. Trends in the variables that would be representative for the role incompatibility hypothesis and the ease in combining work and child-rearing (working hours, proportion females employed part time, or gross enrolment ratio of kids in preprimary education) cannot be related to the trends in fertility. In summary, the analysis in Engelhardt and Prskawetz (2004) indicates that the fact that fertility declined most among low female participation countries can partly be explained by three variables that showed a distinct pattern for low female participation countries. These are female unemployment rate, the mean age at first birth and the share of family allowance for first children. Many of the variables they considered show parallel trends for low, medium and high participation countries, but those changes induced a more pronounced drop in total fertility values in low female labour force participation countries which are more likely to adhere strong family values and social norms that still see women as the main provider of childrearing activities. 
de Laat and Sevilla-Sanz (2005) set up a model of household production that focuses on the heterogeneity in attitudes towards women's home time and the externalities associated with a man's willingness to participate in home production. Within their framework they are able to explain the negative association between female labour force participation and total fertility at the micro-level as well as the positive association between female labour force participation and total fertility at the macro-level. More specifically, they show that households with less egalitarian attitudes have a more unequal division of household tasks, lower female labour force participation and more children and term this relation the household attitude effect. However, at the macro-level the social externality effect works: households living in less egalitarian countries have, ceteris paribus, a more unequal division of household tasks, lower female labour force participation and also fewer children. The interaction of the household attitude and the social externality effect can cause the change in the cross-country correlation. In particular, they show that in egalitarian countries when relative female wages rise men's contribution to the household production becomes higher allowing the social externality effect to dominate. To summarize, the paper by de Laat and Sevilla-Sanz is the first one to provide a unified theoretical underpinning of the negative micro-level correlation, the positive macro-level correlation as well as the change in the correlation of total fertility and female labour force participation over time. Their basic argument is that changes in socio-economic trends, like the increase of female labour force participation, may have caused the underlying differences across countries in attitudes, social norms and culture to uncover! Put differently, changes in the socio-economic context may help to uncover long-term cultural and institutional differences across countries. Since the socio-economic context may change faster as the underlying cultural and social norms, a change in the cross-country correlation of the total fertility and female labour force participation results.

A key argument in de Laat and Sevilla-Sanz is the micro-macro interactions, i.e. individual choices, opportunities and constraints interact with their social context (cf. also Billari 2004). Several authors have emphasized the importance of social interactions for fertility choices (Bongaarts and Watkins 1996; Montgomery and Casterline 1996; Bernardi 2003). A recent contribution that emphasizes the relevance of social interactions in the context of low fertility is Kohler et al. (2002 and 2006). Social interactions (either impersonal through e.g. labour market, or personal ones through e.g. peer groups) may induce multiplier effects, multiple equilibria and status-quo enforcement and path dependence (Billari 2004). Similarly, Aberg (2003) found positive effects of the proportion of peers married on the marriage rate, indicating that social interaction is in part driving individuals' marital decisions.

As we argue in this paper the change in socio-economic context (e.g. the labour markets, the educational systems, the sexual revolution, etc.) combined with the rather rigid patterns of cultural norms, values and institutional settings together with multiplier effects through social interaction mechanisms may explain the change in the cross-country correlation between fertility and key fertility-related demographic behaviour. ${ }^{1}$ One should not get

\footnotetext{
${ }^{1}$ A similar argument has recently been put forward by Gauthier (2002) and Billari (2004). Though global macro-level factors have brought some convergence in institutions, values, and behavior, national-level
} 
trapped into the ecological fallacy and translate these changes in the cross-country correlation to the experience of single countries over time. As we will show, postponement of first birth and first marriage and increasing divorce rates and extra-marital births are associated on average with lower fertility viewed from a time series perspective within each country. However, increases in age at first birth and first marriage and percentage of extra-marital births have a progressively less negative effect on fertility over time.

Our choice to focus on key fertility-related behaviour is inspired by the findings in Engelhardt and Prskawetz (2004), who found that the trend of fertility-related demographic indicators is compatible with the trend in total fertility over the last four decades of the previous century. As the authors argue, marriage and divorce and mean age at first birth are still valid determinants of fertility behaviour since the overall decline in the total fertility rate was accompanied by a decline in first marriage rates and increase in divorce rates and ages at first births. However from a cross-sectional view neither the marriage rate nor the divorce rate and mean age at first birth is positively, respectively negatively in case of divorce rates and mean age at first birth, correlated to fertility as is also shown in Billari and Kohler (2004). First marriage rates and total fertility may still be closely interdependent in countries where long-term commitment to partnership remains the norm. In these countries (e.g. Italy) any decrease in first marriage rates (caused for instance by declining economic status of men and women) may therefore be linked to a pronounced decrease in total fertility. Long-term partnership commitments in many of the low female labour force participation countries may have been an obstacle rather than a fortune for fertility. In high female labour force participation countries the decline in female first marriage rates and the increase in divorce rates and mean age at first birth were independent of the economic status of male and females and more a sign of liberal partnerships. In summary, these findings indicate that the less fortunate economic conditions in low female labour force participation countries may have had a profound impact on these key fertility-related determinants of fertility and therefore reinforced the direct negative impact of economic conditions on fertility.

In the current paper we provide an econometric study of the hypotheses laid out in Engelhardt and Prskawetz (2004) as well as Billari and Kohler (2004). We investigate whether unmeasured country and time heterogeneity in key fertility-related determinants of fertility can explain the change in the cross-country correlation coefficients of these indicators and total fertility rate. Referring to the argument in de Laat and Sevilla-Sanz (2005) the change in the cross-country correlation between total fertility and fertility-related behaviour may indicate a change in social context of this fertility-related behaviour that has helped to uncover cross-country differences in social norms, culture and institutional settings. To uncover the change in social context we test for time heterogeneity in the effect of key fertility-related determinants of fertility on the total fertility rate. To test for cross-country differences we test for country heterogeneity in the effect of key fertilityrelated determinants on the total fertility rate. Note, that by testing for time and country heterogeneity in the effect coefficients of the independent variables we move beyond the

characteristics have been remarkably persistent. Though all countries have experienced similar socioeconomic trends during the 1990s, institutional heterogeneity and long-term stable cultural factors contribute to stabilize differences across countries. 
standard fixed effects modelling approach which ignores heterogeneity in the effect coefficients and only controls for time invariant country effects.

A recent paper by Giuliano (2006) on living arrangements in Western Europe indicates that indeed the sexual revolution of the 1970s may have constituted such a change in the social context of a key fertility-related demographic behaviour, namely the age at leaving parental home. As argued in her paper, "the sexual revolution of the 1970 s - by liberalizing parental attitudes - had a differential impact on living arrangements in Northern and Southern Europe ..." (Giuliano 2006, p. 2). The argument is that Southern Europe's culture of a "strong family" (Dalla Zuanna and Micheli 2004) has been uncovered through the sexual revolution that decreased the privacy costs of staying at home. On the other hand, for Northern Europe the cultural norm was always the independence of generations and hence the sexual revolution had a negligible impact on living arrangements for the Northern European family type.

Identifying potential explanations of the change in the cross-country correlation between the total fertility rate and key fertility-related demographic behaviour serves a further important clarification (besides the identification of underlying differences in cultural and social norms across countries and changes of social context over time). In our empirical analysis we summarize key fertility-related demographic behaviour through period indicators, such as the mean age at first birth, the mean age at first marriage, the total divorce rate and the percentage of extra-marital births. Most of the recent demographic literature argues that at the individual level the postponement of key demographic events that are related to the formation of new households and families (like mean age at first marriage and first birth) as well as increasing instability of marriages (total divorce rate) may be related to lower overall fertility (Kohler et al. 2006). A change in the cross-country correlation between total fertility and these key fertility-related demographic behaviour from negative to positive may indicate a weakening of these relationships for several countries and possibly over time for all countries. The explanatory power of such a hypothesis can be investigated within our proposed econometric framework. In particular, we shall apply pooled time series analysis to explain the reversal of the cross-country correlation between period fertility and key fertility-related demographic indicators. We use data from the Council of Europe and focus on the EU-25 and the period 1975-2001.

\section{Data and Methodology}

\subsection{Data}

In the empirical analysis we assembled annual time series of the total fertility rate (TFR), the mean age at first birth (MAFB), the mean age at first marriage (MAFM), the total divorce rate (TDR) and the percentage of extra-marital births (EXMB) from 1960 to 2001 for all EU countries, except Malta and Cyprus, for which data were not available for many of the indicators used. Our main data source is the Council of Europe (2005). Its data are based on computations using primary data on events by age and population structure and procedures that are standardised for all the countries by the European Demographic 
Observatory. When data are not available for some years we rely on Eurostat data, after controlling for the compatibility and continuity in the data between the two sources.

The total period fertility rate is defined as the average number of children that would be born alive to a woman during her lifetime if she experiences a given set of age-specific fertility rates observed in a population during a given year. The mean ages at first birth and at first marriage for a given year are defined as weighted averages of the different ages with weights being the age-specific rates. The total divorce rate is defined as the probability of divorce for a married person if he or she were to pass through his/her marriage years conforming to the duration-specific divorce rates of a given year. The rate refers to a synthetic marriage cohort. The percentage of extra-marital births is calculated as the ratio between the number of births born out-of-wedlock and the total number of live births.

Figure 1. Correlation between TFR and key fertility-related variables. EU-23, years 1960-2001

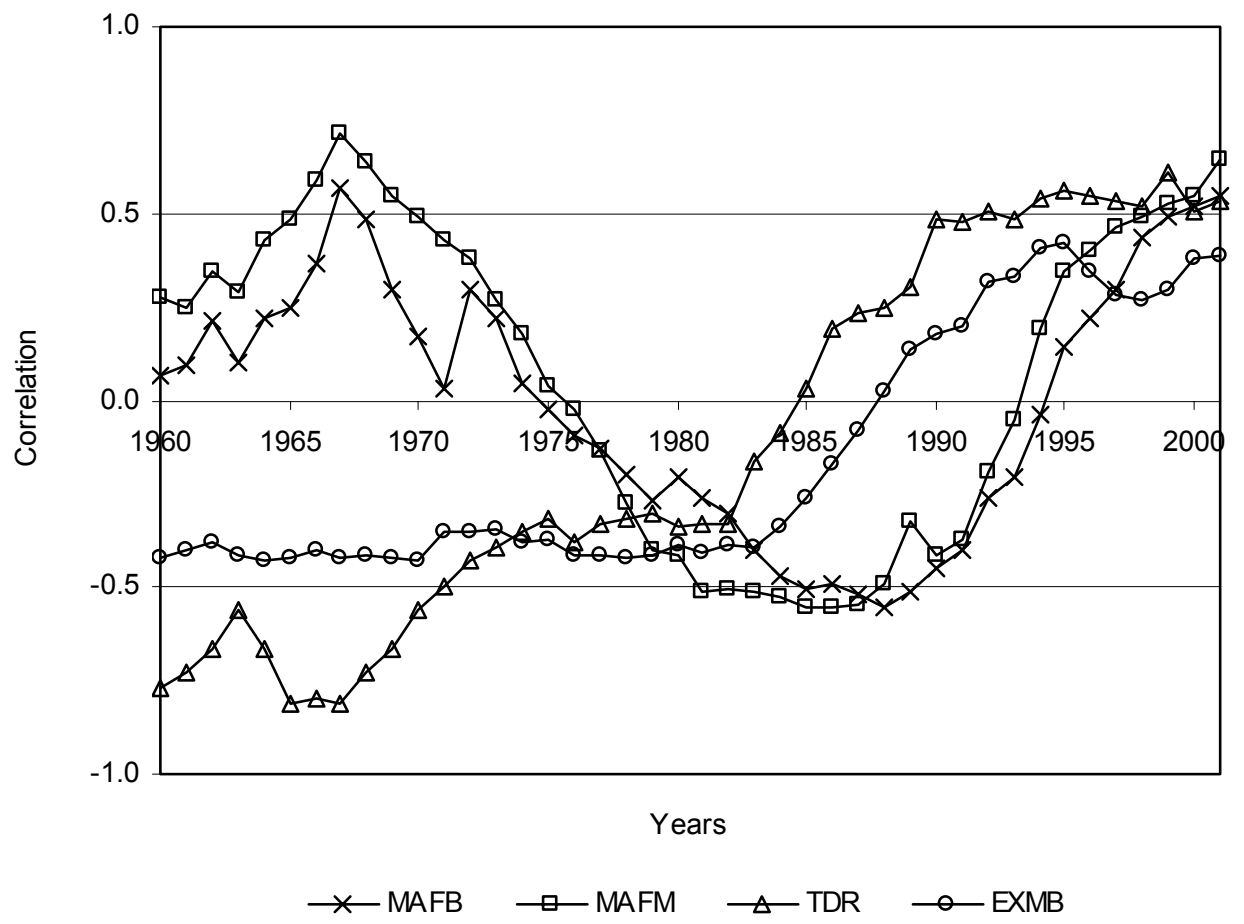

Note: Malta and Cyprus are excluded. However, the number of countries included for the correlation analysis varies for the four indicators over time according to the availability of data.

Source: own elaboration on Council of Europe and Eurostat data.

In Figure 1 we plot the cross-country correlation between TFR and key fertility-related indicators in 1960-2001. Focusing on the period since $1975^{2}$, for all indicators we observe a

\footnotetext{
${ }^{2}$ As indicated later on, the positive cross-country correlation between fertility and age at first birth and age at first marriage in the 1960s and 1970s requires a different conceptual framework, which we will not discuss in the paper.
} 
change in the correlation coefficients from negative to positive. In case of total divorce rates and extra-marital births, this change already occurred in the mid to late 1980s. For the mean age at first marriage and at first birth the change occurred in the first half of the 1990s.

Figures 2a-2e summarize the time patterns of TFR and key fertility-related demographic indicators grouped into four major regions in Europe who differ with respect to welfare state and gender regime: Western Europe (Austria, Belgium, France, Germany, Ireland, Luxembourg, the Netherlands, UK), Northern Europe (Denmark, Finland, Sweden), Southern Europe (Greece, Italy, Portugal, Spain) and Central/South-Eastern Europe (Czech Republic, Hungary, Poland, Slovak Republic, Slovenia, Estonia, Latvia, Lithuania). ${ }^{3}$

For all the EU-23 countries a pronounced drop in fertility from values well above the level necessary for generational replacement in the 1960s to below replacement fertility levels in the late 1990s can be observed (Figure 2a). Northern European countries were the forerunners in these developments and fertility already declined below an average number of two children per woman in the late 1960s. Western Europe followed this trend by a delay of about 7 years and countries in Southern Europe joined the low fertility levels by the early 1980s. Countries in Central/South-Eastern Europe are amongst the latest in terms of fertility drops below replacement levels. While fertility in countries in Western and Northern Europe stabilized on average at values above 1.5, countries in Southern and Central/South-Eastern Europe are among the lowest-low fertility countries (Kohler et al. 2006) since the late 1990s.

As discussed in detail in Kohler et al. (2006) important differences in key fertility-related demographic behaviour exist between the two groups of lowest-low fertility. The Southern European pattern is characterized by late home leaving, low prevalence of cohabitation and extra-marital fertility (Figure 2e) and the centrality of marriage and low levels of divorce (Figure $2 \mathrm{~d}$ ). The pattern of late home leaving combined with the centrality of marriage for family formation results in rather high ages at first birth (Figure 2b) and first marriage (Figure 2c) for countries belonging to Southern Europe. The pattern among countries of Central- and South-Eastern Europe is more diverse and characterized by earlier home-leaving, lower rates of marriage and higher rates of divorce (Figure 2d) and extramarital fertility (Figure 2e). Earlier home-leaving results in rather low ages at first birth (Figure 2b) and first marriages (Figure 2c) for those countries.

However, later childbearing and changing family contexts of childbearing are not necessarily causing the lowest-low fertility levels. Countries in Northern Europe are characterized by high ages at first birth (Figure 2b) and at first marriage (Figure 2c), high levels of divorce rates (Figure $2 \mathrm{~d}$ ) and by far the most pronounced share of extra-marital births (Figure 2e). Nevertheless, fertility in Northern European countries is amongst the highest in the EU. Countries in Western Europe show a similar pattern of postponement in first births and first marriages and increases in divorce rate. However, the share of

\footnotetext{
${ }^{3}$ We use unweighted averages over countries in each region since our purpose is to show regional differences and changes that capture also trends in smaller countries in each region.
} 
extra-marital births is more in the order of the values observed for countries in Central/South-Eastern Europe (Figure 2e).

In summary, Figures 2a-2e indicate a pronounced shift in the relationship between fertility and key fertility-related demographic behaviour starting in the 1980s. The age at first marriage and first birth, total divorce rates and the share of extra-marital births are no longer signs of lowest-low fertility in a cross-sectional comparison. During the 1960s and 1970s a similar argument would hold if we restrict our analysis to the mean age at first birth and mean age at first marriage. Countries in Southern Europe have always been characterized by relatively high ages at the onset of union formation and childbearing. However, since the positive cross-country correlation between fertility rates and age at first birth and first marriage in the 1960s and 1970s would require a different conceptual framework as the positive cross-country correlation we observe in the late 1980s and 1990s, we will restrict our analysis to the period since 1975 in the following.

Figure 2a. Total fertility rate. EU-23 grouped in four major regions, 1960-2003

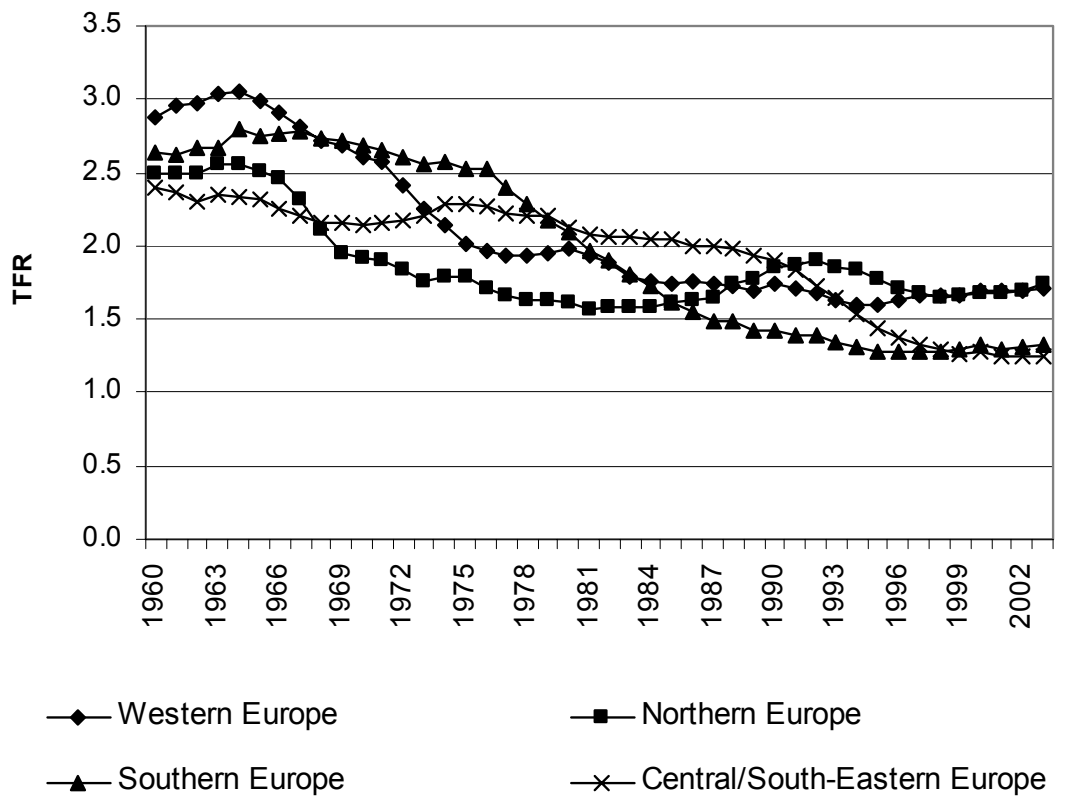


Figure 2b. Mean age at first birth. EU-23 grouped in four major regions, 1960-2003

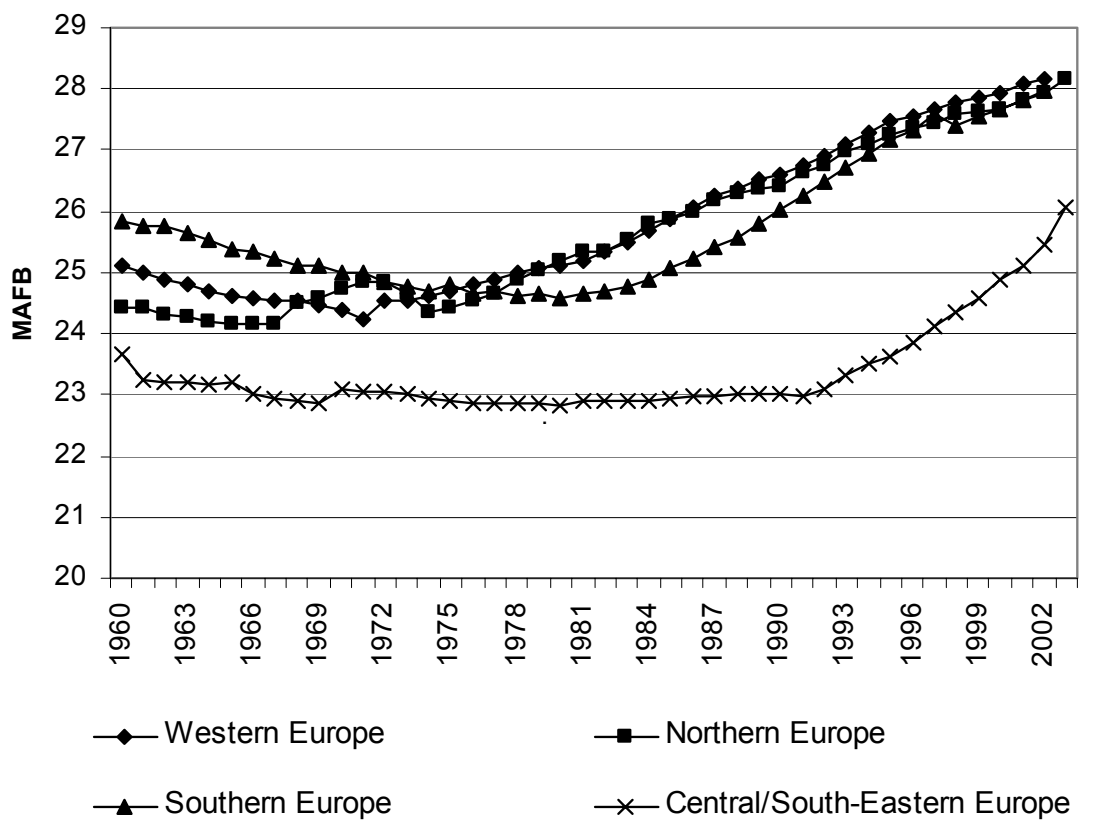

Figure 2c. Mean age at first marriage. EU-23 grouped in four major regions, 1960-2003

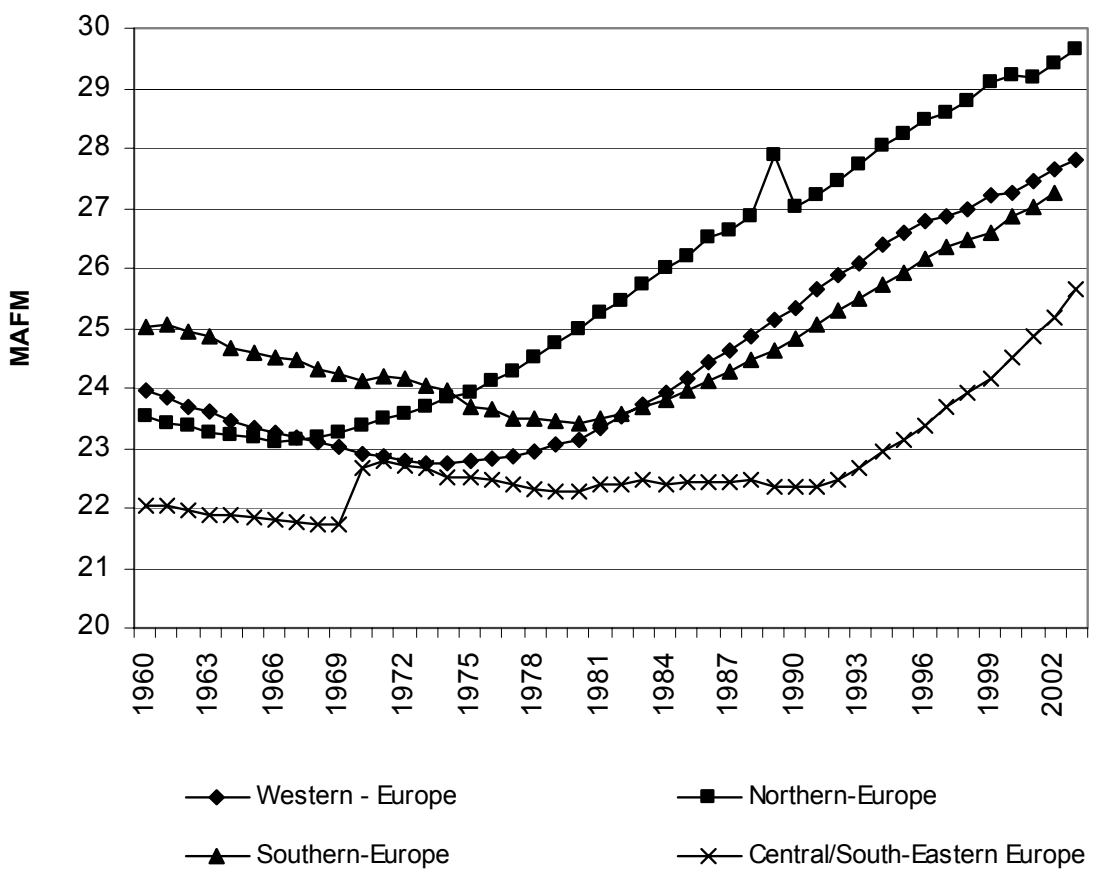

Note: the discontinuity in the time series for Central/South-Eastern Europe in 1970 is due to the fact that for the time period prior to 1970 the average value of MAFM is only based on 3 countries as compared to 7 countries from 1970 onwards. The peak in MAFM in the late 1980s for Northern Europe is due to Sweden where new rules regarding the eligibility for widow's pensions were introduced in 1989. 
Figure 2d. Total divorce rate. EU-23 grouped in four major regions, 1960-2003

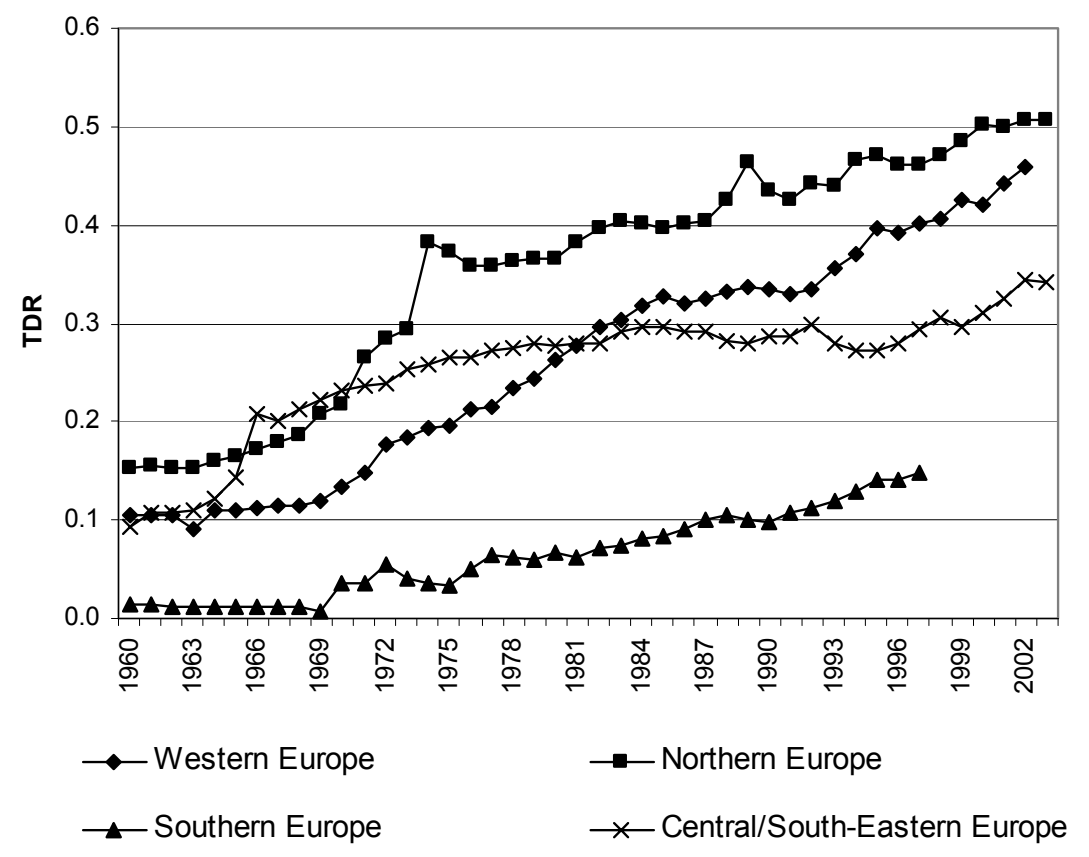

Figure 2e. Extra-marital births (\%). EU-23 grouped in four major regions, 1960-2003

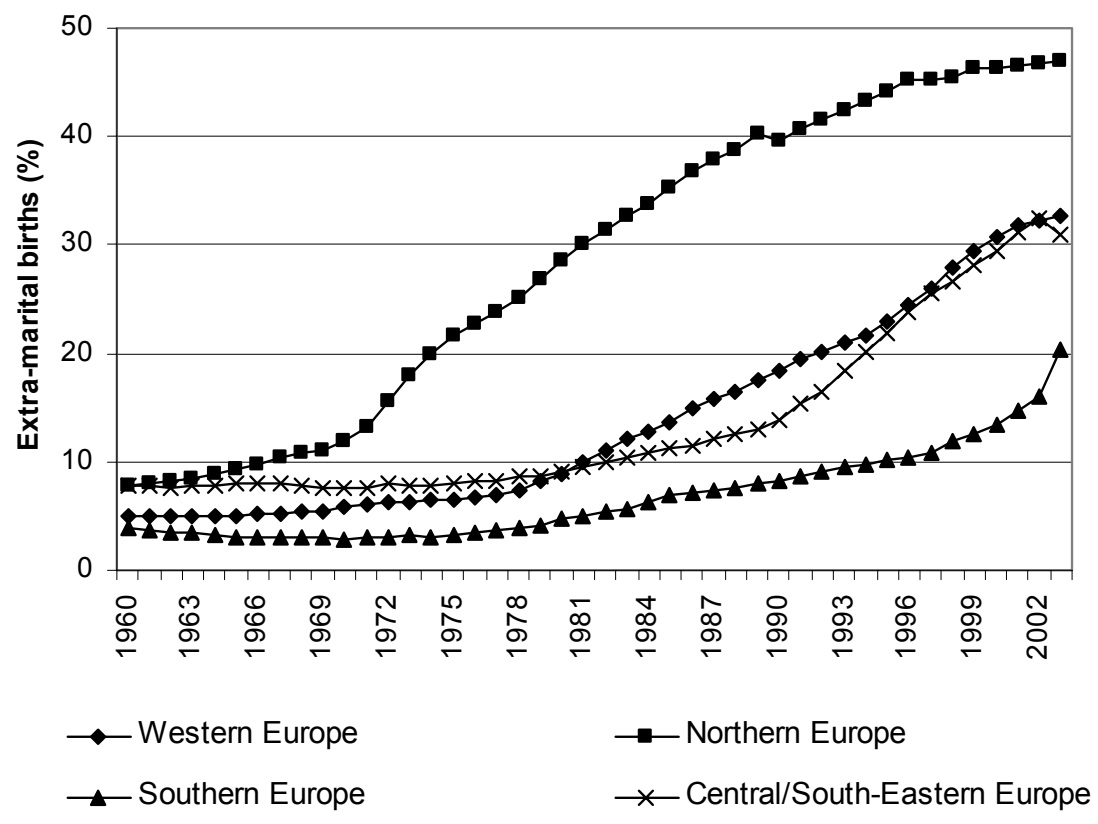




\subsection{Methodology}

Our methodological approach is to pool cross-sectional time series. This technique incorporates both the cross-sectional effect of the independent variables on fertility as well as the time-series effects within nations. The critical assumption of pooled cross-sectional times series models is that of pooling. That is, all units are characterised by the same regression equation at all points in time:

$$
y_{i t}=x_{i t}^{\prime} \beta+\varepsilon_{i t} ; \quad i=1, \ldots, N ; t=1, \ldots, T
$$

where $y_{i t}$ and $x_{i t}$ are observations for the $i$-th unit at time $t$ and $\beta$ is a vector of coefficients. $\varepsilon_{i t}$ is the residual with the usual properties (mean 0 , uncorrelated with itself, uncorrelated with $x$, and homoscedastic).

To deal with causal heterogeneity across space, we apply the fixed effects model as given by:

$$
y_{i t}=x_{i t}^{\prime} \beta+v_{i}+\varepsilon_{i t} \quad i=1, \ldots, N ; t=1, \ldots, T
$$

where $v_{i}$ are assumed to be fixed parameters which may be correlated with $x_{i t}$. Such a model focuses on the within-country variation, and the coefficients represent a crosscountry average of the longitudinal effect.

If the unobserved country-specific heterogeneity, however, can be assumed to be realisations of a random process and uncorrelated with the included variables, then the model is a random effects model. Thus, the crucial distinction between the fixed and the random effects model is whether the unobserved country-specific effect embodies elements that are correlated with the regressors in the model (Greene 2003). Whether the fixed or random effects model should be used is both a substantial and statistical question. If there is no substantial reason to assume a significant correlation between the unobserved countryspecific random effects and the regressors, then the random effects model may be more powerful and parsimonious. If there is such a correlation, the random effects model would be inconsistently estimated and the fixed effects model would be the model of choice. The Hausman specification test is the classical test for statistical model selection. ${ }^{4}$

Both random and fixed-effects panel models do not deal explicitly with temporally and spatially correlated errors often contained in pooled time series models. If there is autocorrelation in the model, it is necessary to deal with it because autocorrelation in the residuals causes seriously inefficient estimates. To control for autocorrelation we apply the static approach where the nuisance in the residuals is modelled as a first-order autoregression or $\mathrm{AR}(1)$ process:

$$
\varepsilon_{i t}=\rho \varepsilon_{i, t-1}+\eta_{i t}
$$

where $\eta_{i t}$, independent and identically distributed with mean 0 and $\rho$, is the so-called autocorrelation parameter, which is less than one in absolute values. In particular in our

\footnotetext{
${ }^{4}$ In our empirical analysis in the following section we could reject the random effects model.
} 
empirical analysis we apply the Prais-Winsten estimator (Prais and Winsten 1954) that transforms the data as follows: $z_{i 1}^{*}=\sqrt{1-\hat{\rho}^{2} z_{i 1}}, z_{i t}^{*}=z_{i t}-\hat{\rho} z_{i t}, t=2, \ldots, T, z=x, y$

\section{Empirical Results}

In the following, we empirically estimate the effect of the mean age at first birth, mean age at first marriage, total divorce rate and extra-marital births on the total fertility rate. We consider available demographic data for EU-25 countries. Due to data limitations, in all the elaborations we exclude Cyprus and Malta; therefore the starting data set counts 23 countries. We focus on the period 1975-2001 (2000 for the mean age at first marriage).

Due to incomplete time series data or rather irregular temporal pattern we had to exclude additional countries in the different analyses. In the analyses where we investigate the relation between the mean age at first birth and the total fertility rate, 16 countries are included: Czech Rep., Denmark, Estonia, Finland, France, Germany, Greece, Hungary, Ireland, the Netherlands, Poland, Slovak Rep, Slovenia, Spain, Sweden, UK. Concerning the mean age at first marriage, we include in the analysis 22 countries. Apart from Malta and Cyprus, we exclude Ireland. Regarding the total divorce rate, we include 13 countries in the analysis: Austria, Denmark, France, Greece, Hungary, Lithuania, Luxembourg, the Netherlands, Poland, Portugal, Slovak Rep., Slovenia, Sweden. Finally, we consider the relation between extra-marital births and fertility. Apart from Malta and Cyprus, we exclude Belgium.

Calculating the cross-country correlation between total fertility and the mean age at first birth and first marriage, total divorce rate, and extra-marital births, we find for the mean age at first birth and first marriage a positive correlation in the 1960s up to the mid 1970s that turned to a negative correlation till the mid of the 1990s and changed again to a positive correlation thereafter (cf. Figure 1). Since the earlier change in correlation is caused by different factors, we focus in our estimates on the period 1975-2001. We first estimate fixed effects models (i.e. controlling for heterogeneity in the intercept) and controlling for possible autocorrelation. We then proceed to consider time and country heterogeneity in the slope coefficients.

\subsection{Prais-Winsten Estimates}

Table 1 summarizes the estimated coefficients of mean age at first birth (MAFB), mean age at first marriage (MAFM), total divorce rate (TDR) and extra-marital births (EXMB) on total fertility using Prais-Winsten models with panel-corrected standard errors and AR(1) disturbances. For all the variables the effect is significantly negative. Additional

estimates (not shown here) yield, that the estimated effect is independent from the estimation procedure. As the value of the R2 statistic indicates, the model fit is extremely good for all indicators. 
Table 1. Fixed country effects Prais-Winsten estimations with panel-corrected standard error and AR(1) disturbances of the effect of MAFB, MAFM, TDR and EXMB on TFR

\begin{tabular}{lcccc}
\hline & MAFB & MAFM & TDR & EXMB \\
\hline Beta & $-0.1449^{* * *}$ & $-0.0606^{* * *}$ & $-0.6424^{* * *}$ & $-0.0218^{* * *}$ \\
Const & $5.1763^{* * *}$ & $3.0598^{* * *}$ & $1.7518^{* * *}$ & $2.0473^{* * *}$ \\
R-sq. & 0.78 & 0.76 & 0.77 & 0.80 \\
Wald $\chi^{2}$ & $418.84^{* * *}$ & $715.94^{* * *}$ & $97.5 * * *$ & $1233.3^{* * *}$ \\
\hline
\end{tabular}

Sign. at level: $* * * \mathrm{p}<0.001 ; * * \mathrm{p}<0.01 ; * \mathrm{p}<0.05 ;+\mathrm{p}<0.1$.

Note: Wald performs a $\chi^{2}$ test for $H_{0}: \beta=0$.

Multiplying the effect coefficients (Beta) with the range in the independent variable observed for EU-23 during the period 1975-2001 (i.e. the range of MAFB, the range of MAFM, etc.) and comparing these values to the range of the TFR values, gives an estimate of the contribution of the independent variable to explain variations in the dependent variable (Table 2; cf. Pampel 2001, p.102). The results of these calculations show that cross-country variation in extra-marital births and mean age at first birth contribute up to $51 \%$ and $43 \%$ respectively to the cross-country variation in TFR. Cross-country variation in mean age at first marriage and total divorce rate contribute much less to variation in total fertility: $33 \%$ in case of the mean age at first marriage and $22 \%$ in case of total divorce rate. Recalling Figure $2 b$ through Figure 2e, these results can be explained by the fact that the trend in the mean age at first birth and extra-marital births show rather distinct patterns for Central/South-Eastern European countries (in case of mean age at first birth) and Northern European countries (in case of extra-marital births).

Table 2. Contribution of key-fertility related variables to the variation in the total fertility rate

\begin{tabular}{lcccc}
\hline & MAFB & MAFM & TDR & EXMB \\
\hline Min & 22.3 & 21.1 & 0.02 & 1.92 \\
Max & 29.2 & 30.4 & 0.60 & 56.21 \\
Diff*beta. & -0.98 & -0.57 & -0.37 & -1.20 \\
TFR min & 1.13 & 1.10 & 1.10 & 1.10 \\
TFR max & 3.43 & 2.82 & 2.82 & 3.43 \\
TFR diff & 2.30 & 1.72 & 1.72 & 2.33 \\
(Diff*beta/TFR diff)* 100 & $43 \%$ & $33 \%$ & $22 \%$ & $51 \%$ \\
\hline
\end{tabular}

Note: Differences in the TFR minimum and maximum values are due to the different countries considered for the four demographic indicators.

Since the coefficients in Table 1 represent a cross-country average of the longitudinal effects of the independent variable, important country and time heterogeneity in these coefficients is ignored. In the next two sections we investigate whether significant country and time heterogeneity in key fertility related indicators exists. 


\subsection{Country and Time Heterogeneity}

Accounting for country heterogeneity we find clear differences between the Central/South-Eastern and Southern European countries and the countries in Northern and Western Europe (Figure 3a through Figure 3d, Table A.1 in appendix).

Figure 3a plots the effect of an increase in the mean age at first birth on the total fertility rate controlling for country heterogeneity. Except for Ireland, the increase in the mean age at first birth had a much smaller effect on TFR in Western and Northern European countries as compared to countries in Central/South-Eastern and Southern Europe. Though the increase in the mean age at first birth reflected a change in the social context (e.g. increasing female education and female labour force participation rates) among all countries, this change translated into a much stronger negative impact on TFR for Central/South-Eastern and Southern European countries. An explanation can be found in the worse economic conditions of Central/South-Eastern and Southern European countries that reinforced - through postponement of fertility- the negative impact of economic conditions on fertility. Moreover, the prevailing cultural and social norms in these countries, particularly in the Southern European countries, imply that postponement of fertility is often a sign of the incompatibility of social change and family formation. Hence, not the increase in the mean age at first birth per se, but the change in the social context that induced an increase in the mean age at first birth, is the factor that explains the fall in TFR in these countries ${ }^{5}$.

We find similar results for the mean age at first marriage (Figure 3b). An increase in the mean age at first marriage induced a much more pronounced decrease in the total fertility rate for Central/South-Eastern and Southern European countries. Such a result supports the idea that marriage and fertility in these countries are intertwined ${ }^{6}$. Note, that Poland and the Slovak Republic are the countries where increases in MAFB and MAFM had the strongest negative impact on TFR. As argued in Oláh and Fratczak (2004), there is clear evidence that women's increasing economic independence (through higher education and labour force participation) has delayed the transition to motherhood in Poland and, similarly, marriage commitments have been postponed. While gender equality has been supported in the public sphere, the division of family responsibilities remained rather traditional. Consequently, the delay in fertility often implies forgoing of fertility in these countries. Moreover, in many of the countries of Central/South-Eastern Europe changes in patterns of union formation have been observed during the last decade, such as decline in marriage

\footnotetext{
${ }^{5}$ Thus, it has to be pointed out that the much stronger negative association between the mean age at first birth and total fertility, observed in Ireland, Central/South-Eastern and Southern Europe may be related not only to a change in fertility timing, but also intensity, either following the overall fertility decline observed since decades across Europe or reflecting the change in the social context. In case of a mere change in timing, the effect on the period TFR is mechanical: an increase in the mean age at first birth inflates the total fertility rate. In the second case, to the change in fertility timing has to be added a downward change in the fertility outcome that also contributes to the decline of the period TFR.

${ }^{6}$ Even though from a cross-sectional point of view it has been revealed an increasing disconnection between marriage patterns and fertility levels after the emergence of lowest-low fertility in many of these countries during the 1990s (Billari and Kohler 2004).
} 
rates and increase in cohabitation, and these changes, translated also in later marriages, seem to still influence reproductive behaviour decisions. Contrarily, in Western European and Northern European countries, the social context that induced an increase in the mean age first marriage and the spread of new forms of family formation was rather independent of the decision of fertility as our results in Figure $3 b$ indicate.

Country heterogeneity is also prevalent if we consider the total divorce rate (Figure 3c) and the share of extra-marital births (Figure 3d). Again, increases in both indicators implied a more pronounced decrease in total fertility rates in Central/South-Eastern and Southern European countries. The results for Southern European countries are rather straightforward. Strong family values and social norms together with the centrality of marriage and low prevalence of divorce and extra-marital births imply that an increase in TDR and extra-marital births will induce a decline in TFR. However, in the Central/South-Eastern European countries divorce and extra-marital fertility was always pronounced (Figure 2d and 2e). The fact, that a further increase in these indicators is related to a decline in fertility may therefore indicate that factors that induced these changes in TDR and extra-marital births (e.g. increasing economic uncertainty and change in values, norms, attitudes; cf. Philipov 2002) may also induce the fall in fertility, and, in addition, that these dimensions, i. e. TDR and extra-marital births, on the one hand, and total fertility, on the other, are not so directly linked, as it emerges for Southern Europe.

Figure 3a. Country specific effects for MAFB

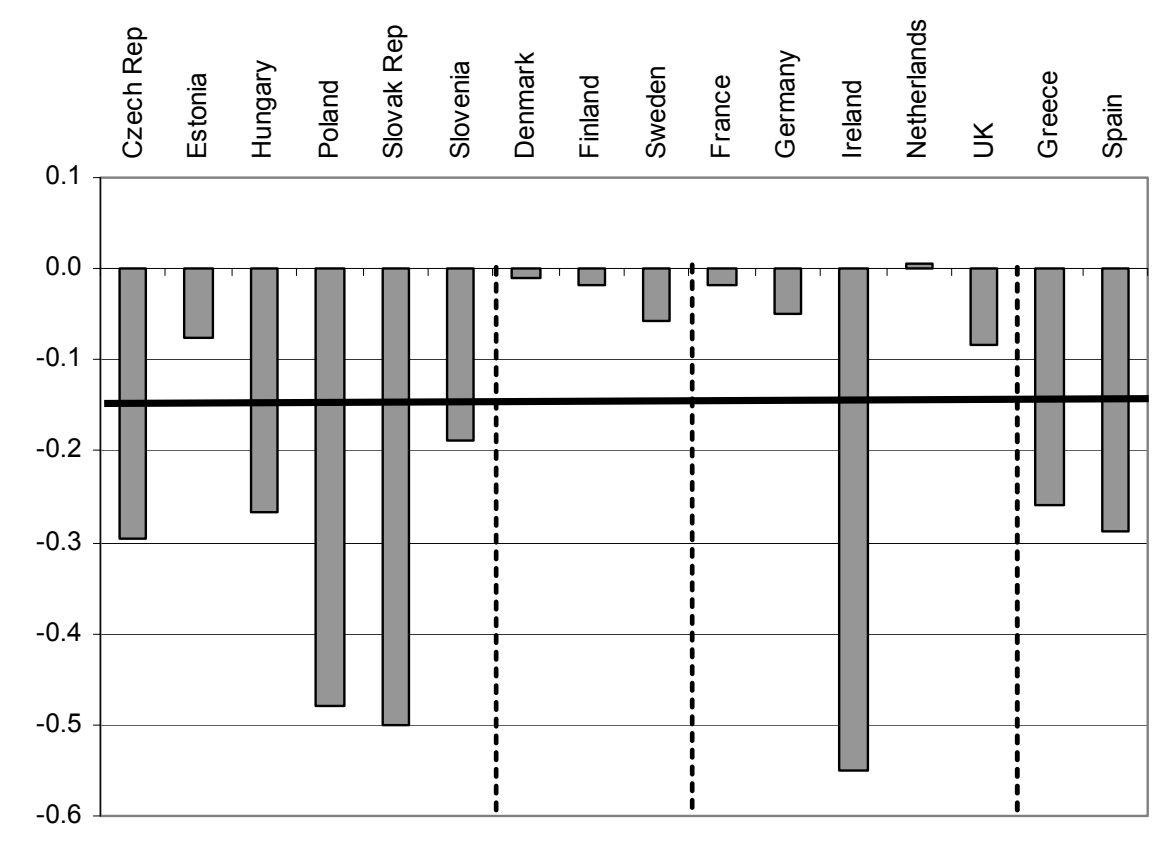

Remark: The bold horizontal line at -0.15 indicates the average effect of MAFB over all countries (cf. Table 1). The vertical lines separate the country groups: Central/South-Eastern Europe, Northern Europe, Western Europe and Southern Europe. 
Figure 3b. Country specific effects for MAFM

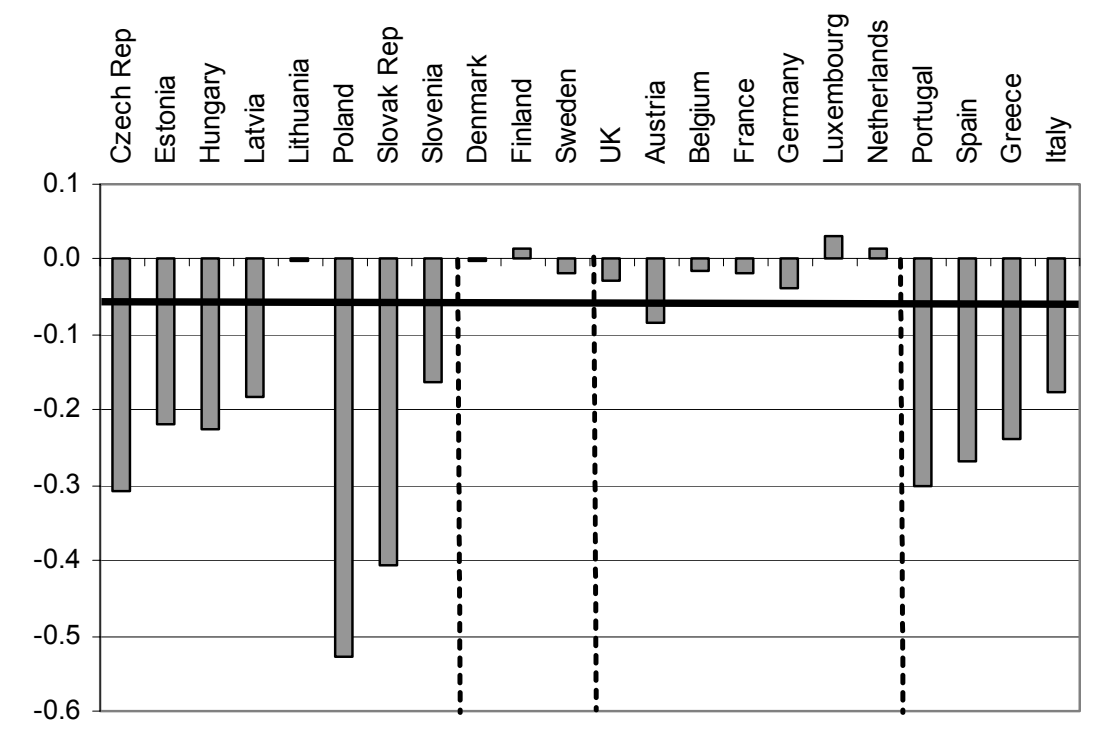

Remark: The bold horizontal line at -0.06 indicates the average effect of MAFM over all countries (cf. Table 1). The vertical lines separate the country groups: Central/South-Eastern Europe, Northern Europe, Western

Figure 3c. Country specific effects for TDR

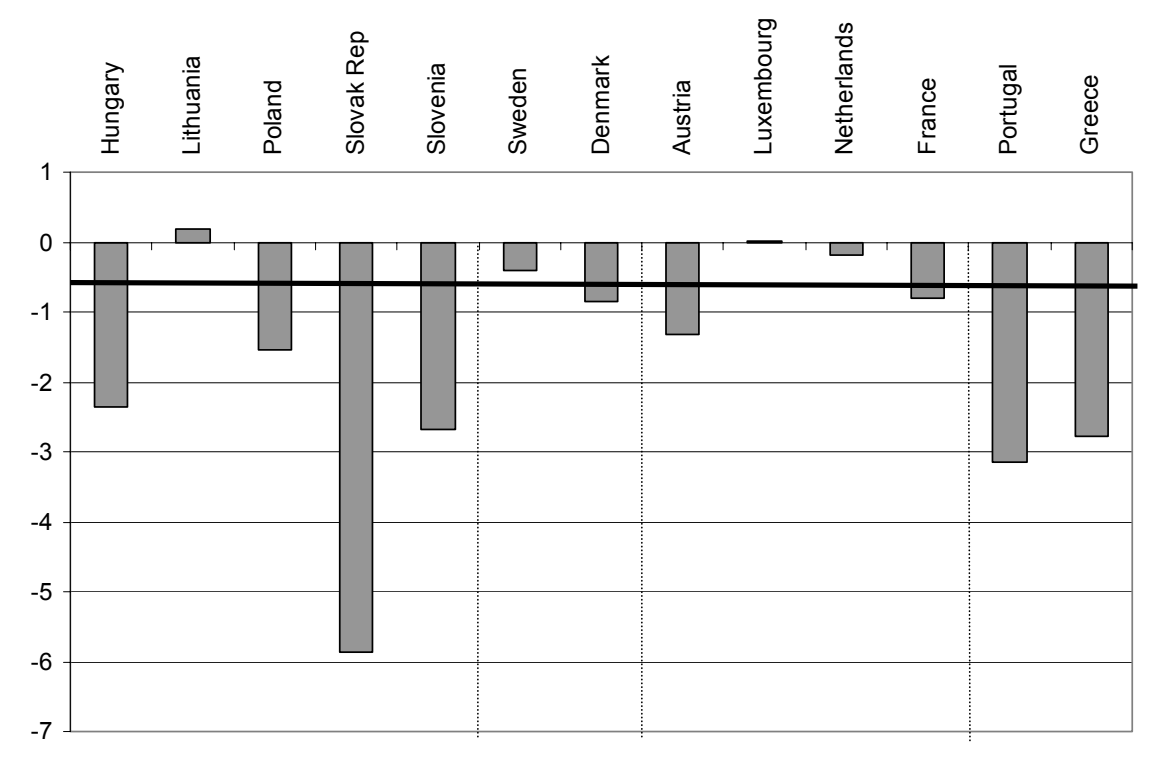

Remark: The bold horizontal line at -0.64 indicates the average effect of TDR over all countries (cf. Table 1). The vertical lines separate the country groups: Central/South-Eastern Europe, Northern Europe, Western Europe and Southern Europe. 
Figure 3d. Country specific effects for extra-marital births

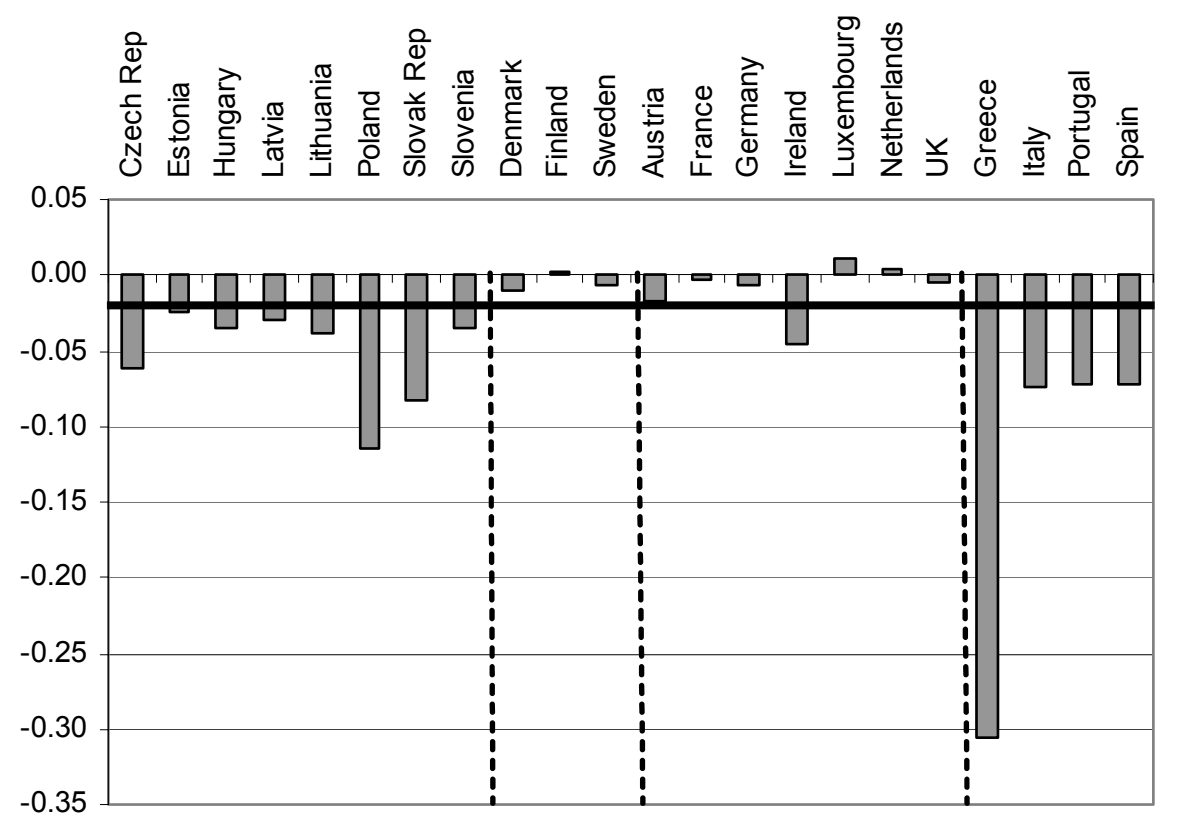

Remark: The bold horizontal line at -0.02 indicates the average effect of extra-marital births over all countries (cf. Table 1). The vertical lines separate the country groups: Central/South-Eastern Europe, Northern Europe, Western Europe and Southern Europe.

So far, our results indicate that it is important to control for unobserved country heterogeneity in the intercept (Table 1) as well as slope (Figures 3a-3d) of the relation between fertility-related demographic indicators and the total fertility rate. In this section we study whether time heterogeneity in the negative association between TFR and key fertility-related demographic factors is prevalent as well. Due to numerical instability of the estimation procedures, we refrain from models of three way interaction, i.e. country and time heterogeneity in the slope coefficient, and only concentrate on time heterogeneity in the slope coefficient.

To test explicitly for a time change in the effect of MAFB (respectively MAFM, TDR, extra-marital births) on fertility, we estimated a model with interaction effects between the independent variables and time. To account for a flexible relation over time, we applied two-year time dummies. The result of the Prais-Winsten estimation (Table A.2 in appendix) is graphically displayed in Figure 4.

Considering time heterogeneity in the negative time series association, we find for all indicators that the negative effect on TFR declined over time and even turned positive during the last periods. These results indicate that changes in social context that underlie the trends in the demographic indicators are less negatively related to fertility levels over time, reflecting a certain acceptance in reproductive behaviour decision-making of the new social context. Nevertheless, it is clearly a matter of time to see whether in countries where the negative association is stronger this acceptance means definitely low fertility or there is some space for recovery. 
Figure 4. Effects of MAFB, MAFM, TDR and extra-marital births on fertility over time

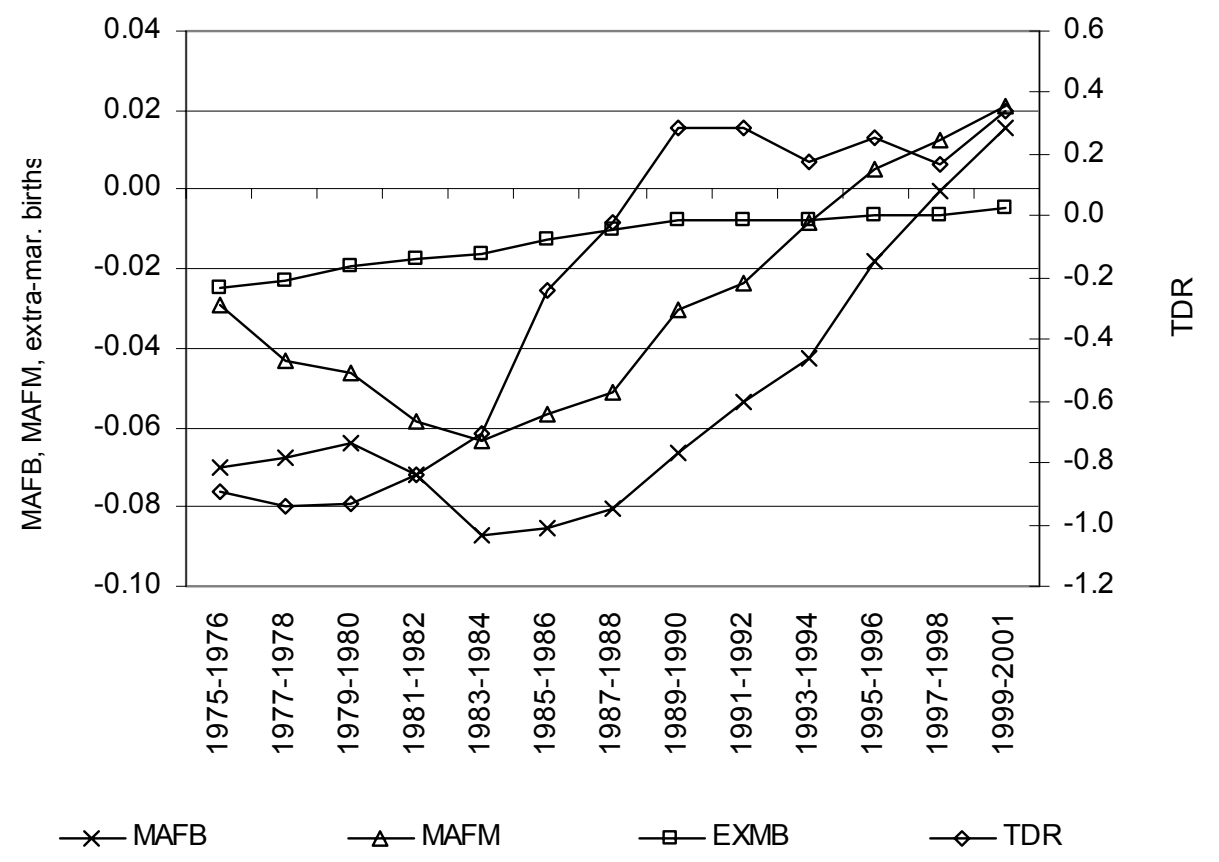

\section{Conclusions}

Summing up, increases in the mean age at first birth and first marriage, total divorce rate and extra-marital births are associated with decreases in total fertility once we control for country heterogeneity, i.e. different social contexts across countries (Table 1). Our analysis therefore confirms also at the aggregate level the recent findings at the micro-level: The postponement of key demographic events that are related to the formation of new households and families (like the mean age at first marriage and first birth) as well as increasing instability of marriages (total divorce rate, extra-marital births) may be related to lower overall fertility.

The extent to which total fertility declines are related to changes in fertility-related demographic indicators is however rather different across countries (Figures 3a-3d). In Northern and Western European countries increases in mean age at first birth and first marriage, total divorce rate and extra-marital births are rather modestly related to declines in total fertility. In those countries, developments of fertility-related indicators represent a sign of more liberal partnerships and increasing opportunities of women in the educational and labour market sector. These changes in the social context did not accelerate the drop in total fertility since prevailing social norms, values and attitudes allowed the compatibility of this changing social context and family formation behaviour. On the other hand, for Central/South-Eastern European and Southern European countries trends in fertility related indicators were closely related to changes in economic conditions (also including the housing sector) in addition to changes in social context (increases of female education and female labour force participation) and increasing uncertainty about future economic and 
social development. These factors that induced the increase in mean age at first birth and first marriage, total divorce rate and extra-marital births were then also related to the drop in total fertility in those countries. Moreover, social norms, values and attitudes put additional restrictions on the process of family formation in those countries that are not compatible with trends in key fertility-related demographic variables.

Though our analysis confirms the negative relation of postponement of key demographic events and fertility, further investigations that also include time heterogeneity in the negative association (Figure 4) indicate that further postponement of demographic events results into less pronounced declines in fertility. These findings support the conclusion that at the macro-level the postponement of key fertility-related demographic events might have a declining negative impact on fertility; in particular in those countries that have adjusted their social, family and labour market policies accordingly.

Our study has identified the importance to control for time and country heterogeneity in understanding the association of postponement of demographic events and increases in instability of marriage on fertility. The next step is to identify the factors underlying these heterogeneities. 


\section{References}

Aberg, Y. 2003. Social interactions. Stockholm studies on social mechanisms. Stockholm: Stockholm University.

Adsera, A. 2004. Changing fertility rates in developed countries. The impact of labor market institutions, Journal of Population Economics 17(1): 17-43.

Ahn N. and Mira, P. 2002. A note on the changing relationship between fertility and female employment rates in developed countries, Journal of Population Economics 15: 667-682.

Benjamin, K. 2001. Men, women, and low fertility: Analysis across time and country. University of North Carolina, Chapel Hill: unpublished manuscript.

Bernardi, L. 2003. Channels of social influence on reproduction, Population Research and Policy Review 22: 527-555.

Billari, F. C. and Kohler, H.-P. 2004. Patterns of lowest-low fertility in Europe, Population Studies 58 (2): 161-176.

Billari, F.C. 2004. Choices, opportunities and constraints of partnership, childbearing and parenting: the patterns in the 1990s, Background paper for the European Population Forum 2004, Geneva, 12-14 January 2004.

Bongaarts, J. and Watkins, S. 1996. Social interactions and contemporary fertility transitions, Population and Development Review 22 (4): 639-682.

Brewster, K.L. and Rindfuss, R.R. 2000. Fertility and women's employment in industrialized nations, Annual Review of Sociology 26: 271-296.

Castles, F.G., 2002, The world turned upside down: below replacement fertility, changing preferences and family-friendly public policy in 21 OECD countries. University of Edinburgh: unpublished manuscript.

Council of Europe, 2005. Recent Demographic Developments in Europe 2004. Strasbourg: Council of Europe Publishing.

Dalla Zuanna, G. and Micheli, G.A. 2004. Strong Family and Low Fertility: A Paradox? New Perspectives in Interpreting Contemporary Family and Reproductive Behaviour. European Studies of Population, Kluwer Academic Publishers, Dordrecht.

de Laat, J. and Sevilla-Sanz, A. 2005. The unequal division of household labor: Gender roles and the puzzle of positive correlation between fertility and female labor-force participation. Brown University: unpublished manuscript.

Engelhardt, H., Kögel, T. and Prskawetz, A. 2004. Fertility and female employment reconsidered: A macro-level time series analysis, Population Studies 58 (1): 109120.

Engelhardt, H. and Prskawetz, A. 2004. On the changing correlation between fertility and female employment over space and time, European Journal of Population 20: $35-62$.

Esping-Andersen, G. 1999. Social Foundations of Postindustrial Economies. Oxford: Oxford University Press.

Gauthier, A.H. 2002. Family policies in industrialized countries: is there convergence?, Population 57 (3): 447-474.

Giuliano, P. 2006. Living arrangements in western Europe: does cultural origin matter? Discussion Paper No. 2042, IZA.

Greene, W.H. 2003. Econometric Analysis, $5^{\text {th }}$ ed. Prentice Hall. 
Kögel, T. 2004. Did the association between fertility and female employment within OECD countries really change its sign?, Journal of Population Economics 17 (1): 45-65.

Kohler, H.-P., F. C. Billari and J. A. Ortega. 2002. The emergence of lowest-low fertility in Europe during the 1990s, Population and Development Review 28 (4): 641-680.

Kohler, H.-P., F. C. Billari and J. A. Ortega. 2006. Low and lowest-low fertility in Europe: causes, implications and policy options, paper presented at the annual meeting of the Population Association of America, LA.

Monnier, A. and Guilbert-Lantoine, C. 1996. La conjoncture démographique: 1'Europe et les pays développés d'outre-mer, Population, 16 (4): 1005-1030.

Montgomery, M.R. and Casterline, J.B. 1996. Social learning, social influence and new models of fertility, in: J.B. Casterline, R.D. Lee and K.A. Foote (eds.) Population and Development Review, Supplement 22, Fertility in the United States: New patterns, New Theories: 151-175.

Oláh, L.Sz. and E. Fratczak. 2004. Becoming a mother in Hungary and Poland during State Socialism, Demographic Research, Special Collection 3, Article 9.

Pampel, F. C. 2001. The Institutional Context of Population Change. Chicago: The University of Chicago Press.

Philipov, D. 2002. Fertility in times of discontinuous societal change: the case of Central and Eastern Europe. Max Planck Institute for Demographic Research, Working paper 2002-024, Rostock.

Prais, S.J. and Winsten, C.B. 1954. Trend estimation and serial correlation. Cowles Commission Discussion Paper No. 383, Chicago.

Rindfuss, R. R., Benjamin Guzzo, K. and Morgan, S. P., 2003. The changing institutional context of low fertility, Population Research and Policy Review, 22(5-6), 411-438. 


\section{Appendix}

Table A.1. Main and country specific effects of MAFB, MAFM, TDR, EXMB on fertility; Prais-Winsten regressions with panel-corrected standard errors and AR(1) disturbances

\begin{tabular}{|c|c|c|c|c|c|c|c|c|}
\hline & MAFB & & MAFM & & TDR & & EXMB & \\
\hline Main effect & -0.1962 & $* * *$ & -0.1434 & $* * *$ & -1.6941 & $* * *$ & -0.0462 & $* * *$ \\
\hline & MAFB*country & & MAFM*country & & TDR*country & & EXMB*country & \\
\hline Czech Rep. & -0.0997 & $*$ & -0.1638 & $* * *$ & n.i. & & -0.0159 & $* *$ \\
\hline Estonia & 0.1199 & & -0.0743 & & n.i. & & 0.0226 & $* * *$ \\
\hline Hungary & -0.0713 & + & -0.0806 & ** & -0.6560 & & 0.0115 & * \\
\hline Latvia & n.i. & & -0.0401 & & n.i. & & 0.0157 & $*$ \\
\hline Lithuania & n.i. & & 0.1425 & + & 1.8739 & * & 0.0086 & \\
\hline Poland & -0.2821 & $* * *$ & -0.3837 & $* * *$ & 0.1419 & & -0.0679 & $* * *$ \\
\hline Slovak Rep. & -0.3048 & $* * *$ & -0.2640 & $* * *$ & -4.1667 & $* * *$ & -0.0365 & $* * *$ \\
\hline Slovenia & 0.0066 & & -0.0182 & & -0.9903 & & 0.0121 & $* * *$ \\
\hline Denmark & 0.1853 & $* * *$ & 0.1431 & $* * *$ & 0.8329 & & 0.0363 & $* * *$ \\
\hline Finland & 0.1792 & $* * *$ & 0.1585 & $* * *$ & n.i. & & 0.0491 & $* * *$ \\
\hline Sweden & 0.1387 & $* *$ & 0.1256 & $* * *$ & 1.2749 & + & 0.0400 & $* * *$ \\
\hline Austria & n.i. & & 0.0606 & * & 0.1328 & & 0.0285 & $* * *$ \\
\hline Belgium & n.i. & & 0.1292 & $* * *$ & n.i. & & n.i. & \\
\hline France & 0.1772 & $* * *$ & 0.1235 & $* * *$ & 0.8902 & * & 0.0437 & $* * *$ \\
\hline Germany & 0.1465 & $* * *$ & 0.1043 & $* * *$ & n.i. & & 0.0396 & $* * *$ \\
\hline Ireland & -0.3544 & $* * *$ & n.i. & & n.i. & & 0.0004 & \\
\hline Luxembourg & n.i. & & 0.1748 & $* * *$ & 1.7157 & $* * *$ & 0.0578 & $* * *$ \\
\hline Netherlands & 0.2008 & $* * *$ & 0.1568 & $* * *$ & 1.5011 & $* * *$ & 0.0506 & $* * *$ \\
\hline UK & 0.1122 & $* *$ & 0.1158 & $* * *$ & n.i. & & 0.0421 & $* * *$ \\
\hline Greece & -0.0617 & + & -0.0960 & $* *$ & -1.0854 & & -0.2599 & $* * *$ \\
\hline Italy & n.i. & & -0.0329 & & n.i. & & -0.0279 & $* *$ \\
\hline Portugal & n.i. & & -0.1578 & & -1.4650 & + & -0.0253 & $* *$ \\
\hline Spain & -0.0923 & $*$ & -0.1235 & $* *$ & n.i. & & -0.0252 & $*$ \\
\hline Constant & 6.6254 & $* * *$ & 5.1033 & $* * *$ & 2.1062 & $* * *$ & 2.2232 & $* * *$ \\
\hline R-sq. & 0.88 & & 0.86 & & 0.82 & & 0.90 & \\
\hline Wald $\chi^{2}$ & 1687.38 & $* * *$ & 2562.49 & $* * *$ & 355.08 & $* * *$ & 2248.81 & $* * *$ \\
\hline
\end{tabular}

Sign. at level: $* * * \mathrm{p}<0.001 ; * * \mathrm{p}<0.01 ;{ }^{*} \mathrm{p}<0.05 ;+\mathrm{p}<0.1$

Note: n.i. $=$ not included. 
Table A.2. Effects of MAFB, MAFM, TDR, EXMB and their time interaction on fertility; Prais-Winsten regressions with panel-corrected standard errors and AR(1) disturbances

\begin{tabular}{|c|c|c|c|c|c|c|c|c|}
\hline \multirow[b]{2}{*}{ Main effect } & \multicolumn{2}{|l|}{ MAFB } & \multicolumn{2}{|l|}{ MAFM } & \multicolumn{2}{|l|}{ TDR } & \multicolumn{2}{|l|}{ EXMB } \\
\hline & -0.0532 & $* *$ & -0.0286 & $*$ & -0.2359 & & -0.0125 & $* * *$ \\
\hline & MAFB*tim & & MAFM*time & & TDR $*$ time & & EXMB*time & \\
\hline $1975-1976$ & -0.0170 & & -0.0004 & & -0.6558 & ** & -0.0123 & $* * *$ \\
\hline $1977-1978$ & -0.0146 & & -0.0143 & & -0.7062 & $* *$ & -0.0101 & $* * *$ \\
\hline $1979-1980$ & -0.0105 & & -0.0173 & & -0.6955 & $* * *$ & -0.0067 & $* *$ \\
\hline 1981-1982 & -0.0185 & & -0.0299 & + & -0.6042 & $* * *$ & -0.0049 & $* *$ \\
\hline 1983-1984 & -0.0336 & * & -0.0349 & * & -0.4719 & ** & -0.0035 & * \\
\hline 1985-1986 & -0.0323 & * & -0.0280 & * & -0.0051 & & -0.0001 & \\
\hline $1987-1988$ & -0.0271 & + & -0.0224 & & 0.2188 & & 0.0025 & \\
\hline $1989-1990$ & -0.0130 & & -0.0019 & & 0.5214 & $* *$ & 0.0049 & $* *$ \\
\hline 1991-1992 & -0.0001 & & 0.0051 & & 0.5181 & $* *$ & 0.0049 & $* *$ \\
\hline 1993-1994 & 0.0105 & & 0.0201 & & 0.4105 & * & 0.0049 & $* *$ \\
\hline $1995-1996$ & 0.0349 & * & 0.0334 & * & 0.4936 & * & 0.0063 & $* *$ \\
\hline $1997-1998$ & 0.0529 & $* *$ & 0.0410 & * & 0.4005 & & 0.0062 & $* *$ \\
\hline 1999-2001 & 0.0686 & $* * *$ & 0.0495 & $* *$ & 0.5757 & $*$ & 0.0078 & $* * *$ \\
\hline Constant & 3.1049 & $* * *$ & 2.3954 & $* * *$ & 1.7951 & $* * *$ & 1.9433 & $* * *$ \\
\hline R-sq. & 0.81 & & 0.81 & & 0.83 & & 0.80 & \\
\hline Wald $\chi^{2}$ & 157.06 & $* * *$ & 95.89 & $* * *$ & 94.80 & $* * *$ & 151.15 & $* * *$ \\
\hline
\end{tabular}

Sign. at level: ${ }^{* * *} \mathrm{p}<0.001 ;{ }^{* *} \mathrm{p}<0.01 ;{ }^{*} \mathrm{p}<0.05 ;+\mathrm{p}<0.1$

Note: For MAFM the last period is $1999-2000$. 


\section{VIENNA INSTITUTE OF DEMOGRAPHY}

\section{Working Papers}

Mamolo, Marija, Union Formation, Marriage and First Birth: Convergence Across Cohorts in Austria, Hungary, Northern Italy and Slovenia? VID Working Paper 08/2006.

Goujon, Anne and Samir K.C., Past and Future of Human Capital in Southeast Asia: From 1970 to 2030, VID Working Paper 07/2006.

Lyngstad, Torkild H., Does Community Context have Important Bearings on the Divorce Rate? VID Working Paper 06/2006.

Winkler-Dworak, Maria, The Low Mortality of a Learned Society, VID Working Paper 05/2006.

Kim, Jungho and Alexia Prskawetz, External Shocks, Household Consumption and Fertility in Indonesia, VID Working Paper 04/2006.

Schwarz, Franz, Behavioral Explanation for Educational Health and Mortality Differentials in Austria, VID Working Paper 03/2006.

Schwarz, Franz, The Contributions of Diseases to Increasing Educational Mortality Differential in Austria, VID Working Paper 02/2006.

Goujon, Anne, Vegard Skirbekk, Katrin Fliegenschnee and Pawel Strzelecki, New Times, Old Beliefs: Projecting the Future Size of Religions in Austria, VID Working Paper 01/2006.

Ediev, Dalkhat M., Extension of Fisher's Classical Result on Exponential Dynamics of the Reproductive Value to a Wide Class of Populations, VID Working Paper $10 / 2005$.

Ediev, Dalkhat M., Long-Term Effects of Childbearing Postponement, VID Working Paper 09/2005.

Philipov, Dimiter, Zsolt Spéder, and Francesco C. Billari, Now or Later? Fertility Intentions in Bulgaria and Hungary and the Impact of Anomie and Social Capital, VID Working Paper 08/2005.

Schwarz, Franz, Widening Educational Differentials in Mortality: Analysis for Austria with International Comparisons, VID Working Paper 07/2005.

The Vienna Institute of Demography Working Paper Series receives only limited review. Views or opinions expressed herein are entirely those of the authors. 